\title{
Non Coding CGG Repeat Expansion Diseases: An Update
}

\author{
Dr Rajib Dutta ${ }^{1 *}$, Swatilekha Roy Sarkar ${ }^{2}$ \\ ${ }^{I}$ MD Neurology, India \\ ${ }^{2} \mathrm{MDS}$, Consultant Orthodontist, India
}

\author{
*Corresponding Author: Dr Rajib Dutta, MD, Neurology, India, Email: rajibdutta@ 163com
}

\begin{abstract}
In recent years neurological disorders specifically neurodegenerative diseases have been recognised worldwide and has been diagnosed more and more by clinicians with the ever improving genetic techniques and is currently considered a leading cause of disability and death right from young to elderly age and might surpass the diagnosis of cancer in future as predicted by World Health Organization(WHO).This type of disorders are common in both high-and low-income countries and it is only predicted to increase as time goes by. Expanded trinucleotide repeats are GGGGGC, CAG, CGG, CCG, CTG, CUG, GAA, and GCN etc in the genome are considered to cause major neurodegenerative diseases in general population. Pathogenesis is different for different repeats however time of onset of the disease and severity will depend on trinucleotide repeat number. So, these type of disease comes under category of Trinucleotide repeat expansion disorders (TREDs). Here in this article we further update about the disease spectrum caused by CGG repeat expansion. Founder haplotypes and haploinsufficiency have been identified recently and its analysis in families may reveal a shared haplotype. Attention should be paid not only to familial cases but also to sporadic cases presenting with similar clinical features otherwise the diagnosis can be missed in early stages.
\end{abstract}

Keywords: $C G G$, neurodegeneration, $C G G$ trinucleotide expansion.

\section{INTRODUCTION}

Unstable tandem repeat expansions are involved in a wide variety of neurological diseases which may or may not share similar clinical features. Non coding repeat expansions are known to cause amyotrophic lateral sclerosis (ALS), Fronto temporal dementia (FTD), spinocerebellar ataxias (SCA 1,2,3,6,7,17), Huntingtons disease (HD). Dentatorubro pallidoluysian atrophy (DRPLA), benign adult familial myoclonic epilepsies (BAFME), myotonic dystrophies (DM1). Spino bulbar muscular atrophy (SBMA), Friedreich ataxia (FRDA), Oculopharyngealmu scular dystrophy (OPMD), Jacobsen syndrome, Fragile XE syndrome (FRAXE) to name a few. Gene expansion repeat diseases can arise from 5"UTR, coding exons, introns or even 3"UTR region.

Proposed mechanism can be loss of function, gain of function (polyglutamine/alanine expansion, RNA toxicity and RAN translation). CGG expansion causes disease initiation as well as progression either by sequestration of crucial proteins or by repeat-associated non-ATG translation (RANT) [1]. In this article the focus will be on non coding CGG repeat expansion and diseases associated with it.

Previous literature on CGG repeat expansion disorders mainly focused on Fragile $X$ syndrome (FRAXA/FXS), Fragile $X$ associated tremor/ ataxia syndrome (FXTAS), Fragile X associate primary ovarian insufficiency (FXPOI) [1], but recently, neuronal intranuclear inclusion disease (NIID), oculopharyngeal myopathy with leukoencephalopathy (OPML) and oculopharyngodistal myopathy (OPDM) has been added to the list [4]. These abovementioned diseases can arise from either 5"UTR or intron region. Loss and gain of function in terms of RNA toxicity and RAN translation are thought to be the primary mechanism involved [5].

\section{Diseases CAUSED bY CGG REPEAT EXPANSION}

\subsection{Fragile X Syndrome (FRAXA/FXS)}

FXS first came into light when an affected person presented with intellectual disability, macroorchidism and dysmorphic features [6].It is best known as fragile $\mathrm{X}$ syndrome a term coined by Mr Lubs [7]. The prevalence of FXS is roughly 1 in 7000 females and 1 in 4000 
males [8]. It is also considered as the second leading cause of intellectual disability after Trisomy 21[9].

Polymerase chain reaction based advanced molecular techniques has helped us to identify DNA methylation pattern that provide more sensitivity and specificity in diagnosing the disease rather than karyotyping under microscope which has minimal sensitivity and specificity [10]. Randi Hagerman et al reported autism spectrum disorders (ASD) and attentiondeficit/ hyperactivity disorder (ADHD) in boys with the Fragile $X$ premutation carriers, and even those who do not present clinically, may be at increased risk for an ASD and/or symptoms of ADHD.

If the premutation is identified through cascade testing, then further assessment should be carried out for symptoms of ADHD, social deficits, or learning disabilities [52]. Ursula Froster et al reported female carriers of the fra$X$ premutation have a broad variety of psychopathological symptoms and relatives of fra-X carriers should be assessed regarding genotype phenotype interaction [54].

\subsection{Fragile $X$ Tremor Ataxia Syndrome (FXTAS)}

FXTAS is hereditary neurodegenerative diseases which primarily affects males [11] and have a diverse clinical presentation which can cause diagnostic uncertainty among clinicians.

The root cause and pathomechanism of the disease is still not understood clearly .It is relatively a newly reported disease and more and more case are surfacing with time, however clinicians are not familiar with the variable symptomatic presentation of the disorder which may lead to incorrect diagnosis and management. FXTAS is caused due to the premutation range of expanded CGG repeats in 5' UTR of the FMR1 gene. In FXTAS, fragile X mental retardation protein (FMRP) is produced in normal range but the mRNA level is increased significantly in the brain cells and leukocytes $[12,13]$ which causes more cellular injury, leading to increase morbidity and ataxiai $\mathrm{n}$ aging males [14,15]. In FXTAS, ubiquitinated inclusions have been shown in brains and nonneuronal tissues [21].RAN proteins have been revealed to be a component of the ubiquitinated inclusions in FXTAS [22]. The premutation of carriers of FXTAS are 1 in 260 females [16] and 1 in 813 males [17]. The penetrance of FXTAS depends on the age of the person such as $40 \%$ of males over 50 years of age [18] while $8 \%$ of female scarriers are over 40 years of age [19]. There should be high risk of suspicion of the risk of disease development in the patient's family [11]. Hagerman et al. has reported guidelines and criteria to reduce errors and misdiagnosis [20]. Recently Shoji Tsuji and colleagues have also reported the clinical spectrum of the condition which includes peripheral neuropathy, cognitive decline, ataxia, tremor and brain MRI findings including middle cerebellar peduncles (MCP) sign, white matter involvement cerebellum $>$ cerebrum and high DWI signal intensity[4]. Hoem et al recently reported about the expression of the FMRpolyG, in the absence of any CGG mRNA, is sufficient to cause reduced cell viability, lamin ring disruption and aggregate formation. Furthermore, it was found that FMR poly G to be a long-lived protein degraded primarily by the ubiquitin-proteasome-system. Together this data indicate that accumulation of FMRpolyG protein per se may play a major role in the development of FXTAS [49].

Recently Ma et al used FACS (fluorescenceactivated cell sorting) and liquid chromatography /tandem mass spectrometry (LC-MS/MS) based proteomics for isolating FXTAS inclusions and found highly enriched levels of conjugated small ubiquitin-related modifier 2 (SUMO2) proteins and $\mathrm{p} 62 /$ sequestosome-1 (p62/SQSTM1) protein within the inclusions. Current analysis has also allowed the first direct detection, through peptide sequencing, of endogenous FMRpolyG peptide, the product of repeat-associated non-ATG (RAN) translation of the FMR 1 mRNA. The abundance of the inclusion-associated ubiquitin- and SUMO-based modifiers supports a model for inclusion formation as the result of increased protein loads and elevated oxidative stress leading to maladaptive autophagy [46].

\subsection{Fragile $X$ with Primary Ovarian Insufficiency (FXPOI)}

FXPOI is caused by expanded CGG repeats in 5'UTR of FMR1 gene. Most females carrying CGG repeats in the range of 55-200 have a probability of developing hypergonadotropic hypogonadism resulting in early menopause effectively before the age of 40 years.

It is considered as a premature ovarian failure (POF) with a frequency of 1 in 350 in the general population. Primary ovarian insufficiency leads to positive feedback in hypothalamic gonad axis resulting in elevated level of follicle-stimulating hormone (FSH) .Decreased level of anti- 
Mullerian hormone has also been found in this disorder. The reduced level of estrogen due to ovarian failure in FXPOI leads to endothelial dysfunction [23], bone fracture [24], and early onset of coronary heart diseases [25] and significant perimenopausal symptoms. In addition to all the above women with early menopause also have psychosomatic and mood disorders symptoms in form of anxiety, depression, somatization disorders, and various other psychological problems [26].

Huang et al recently concluded close association between premutation of the FMR1 gene and increased susceptibility to idiopathic POI (POI and diminished ovarian reserve) of each stage and no correlation between intermediate repeat length or allele of the FMR1 gene and the severity of idiopathic POI [45].

\subsection{Fragile Xe Syndrome with Intellectual Disability (FRAXE ID)}

David R. FitzPatrick \& R. Frank Kooy et al [2] described molecular characterization of an autosomal FSFS (Folate sensitive fragile sites) called FRA2A on chromosome 2. An expansion of a CGG repeat within the 5" UTR or promoter region of the respective gene subsequently resulted in silencing of the neighboring gene AFF3. Expansion of the AFF2 CGG repeat causes FRAXE ID.

\subsection{Autistic Spectrum Disorder (ASD)}

R. Frank Kooy\& David R. FitzPatrick et al [3] also reported de novo occurrence of the $7 \mathrm{p} 11.2$ folate-sensitive fragile site FRA7A in a male with an autistic spectrum disorder (ASD) due to a CGG-repeat expansion mutation (450 repeats) in a 5"intron of ZNF713.Mariel Ormazábal et al reported autistic spectrum disorders in one third of the patients, and affects males with higher prevalence [50].

\subsection{Neuronal Intranuclear Inclusion Disease (NIID)}

NIID is a neurodegenerative disease characterized clinically by various combinations of cognitive decline, parkinsonism, cerebellar ataxia and peripheral neuropathy, and neuropathologically by eosinophilic hyaline intranuclear inclusions in the central and peripheral nervous systems as well as in other tissues including cardiovascular, digestive and urogenital organs [29,30,31,32] and age of onset usually ranges from infancy to late adulthood. An autosomal dominant mode of inheritance has been thought $[33,34,35]$ of previously but about two thirds of cases have been reported to be sporadic in nature [31].

Recent advances include characteristic magnetic resonance imaging (MRI) findings, including high-intensity signals in diffusion-weighted imaging (DWI) in the corticomedullary junction and eosinophilic intranuclear inclusions in skin biopsy, has been described as useful diagnostic hallmarks for NIID[36,37]. Recently lot of late adult onset NIID cases has been reported from japan and china which gives us more insight about repeat expansion spectrum $[4,31,35,38$, 39].

Similarity has been found in the MRI findings between NIID and FXTAS and the presence of eosinophilic intranuclear inclusions[21,31,35].It is found that NIID shares a common molecular basis with FXTAS - a disease caused by mildly expanded CGG repeats (premutation) in the $5^{\prime}$ untranslated region (UTR) of FMR1, with 55200 repeat units.[11] By TRhist technique [40] recently few researchers found accumulation of short reads filled with CGG repeats in the $5^{\prime}$ UTR of NBPF19 (NOTCH2NLC) in NIID.

Fiddes et al. [41] reported that NBPF19/NOT CH2NLC (NOTCH2NLC-like paratype) had variable copy numbers with the frequencies of zero, one and two copies being 0.4, 6 and 92\%, respectivel, indicating that haploinsufficiency of NBPF19 is unlikely to cause NIID.

\subsection{Oculo Pharyngeal Myopathy with Leukoencephalopathy (OPML)}

Noncoding CGG repeat expansions has been found in oculopharyngeal myopathy with leukoencephalopathy in LOC642361 locus with mild ataxia, tremor, oculopharyngeal myopathy, white matter involvement (cerebrum>cerebellum) with high DWI signal intensity [4]

\subsection{Oculo Pharyngo Distal Myopathy (OPDM)}

It is considered as an autosomal dominant disease and its non coding CGG repeat expansion in LRP12 locus in 5"UTR presents with characteristic distributions of muscle involvement, including ptosis, external ophthalmoplegia and dysphagia because of the weakness of the masseter, facial, pharyngeal and distal limb muscles [27, 28, 42] with no specific brain MRI findings and pathologically characterized by tubulo filamentous inclusions $[4,42,43]$.

Till date cause of OPDM is not well understood, however biopsied muscle specimens of 17 
families and 17 sporadic patients with OPDM confirmed the presence of myopathic changes with rimmed vacuoles (which is consistent with the diagnosis of OPDM) [44].

\section{DISCUSSION}

These trinucleotides CGG repeat expansion disorders (TREDs) which we have discussed primarily affects the nervous system and commonly lead to neurodegeneration through toxic protein gain or loss of function, and toxic RNA gain-of-function mechanisms. However, recent advancement in genetics which discovered unconventional Repeat Associated Non-AUG (RAN) translation from putatively non-coding regions of the genome has made things more difficult and complicated for clinicians and researchers to predict the genotype and phenotype of this type of diseases. Mechanism of RAN translation and how nucleotide repeats such as RNA and translated proteins influence liquid-liquid phase separation, membrane less organelle dynamics, and nucleocytoplasmic transport need more understanding [5].

Alexander E Linsalata et al recently reported multiple modifiers of toxicity and RAN translation from an expanded CGG repeat in the context of the FMR1 5"UTR. These include the DEAD-box RNA helicase belle/DDX3X, the helicase accessory factors EIF4B/4H, and the start codon selectivity factors EIF1 and EIF5. Disrupting belle/DDX3X selectively inhibited FMR1 RAN translation in Drosophila in vivo and cultured human cells, and mitigated repeatinduced toxicity in Drosophila and primary rodent neurons. These findings implicate RNA secondary structure and start codon fidelity as critical elements mediating FMR1 RAN translation and identify potential targets for treating repeat-associated neuro degeneration in future [47]. Ma et al reported screening for CGG repeat expansion mutation in FMR1 gene as a recommended investigation in women with the history of spontaneous abortion or induced abortion due to delayed growth of the embryos [48]. Thomas L. Wise reported FXS patients also frequently have autistic-like symptoms, suggesting that the signaling pathways affected in FXS may overlap with those affected in autism. He also suggested that the pathways altered by the loss of the FMR1-encoded protein (FMRP) may overlap with the pathways affected by changes in Igf signaling or that one or more of the proteins that play a role in Igf signaling could interact with FMRP. IGF2 may play a more important role in altering the AGS phenotype (and possibly autism) than IGF1 [51]. $\mathrm{H}$ Zhang et al reported previously about reelin gene alleles and susceptibility to autism spectrum disorders in polymorphic trinucleotide repeat (CGG/GCC) diseases [53].

\section{CONCLUSiON}

Hereby, we further expand the disease spectrum caused by mutation of CGG repeat motif. With further development of genetic techniques, more diseases related to this trinucleotide repeat expansion is expected to be reported in near future. More studies are required at molecular level to understand the real mechanism about the unstability of short microsatellite sequences, RAN translation, organelle dynamics and nucleocytoplasmic transport.

\section{ACKNOWLEDGMENT}

The author has no relevant affiliations or financial involvement with any organization or entity with a financial interest in or financial conflict with the subject matter or materials discussed in the manuscript. This includes employment, consultancies, honoraria, stock ownership or options, expert testimony, grants or patents received or pending, or royalties.

\section{REFERENCES}

[1] Amit Kumar et al., (2019) Exploring the Potential of Small Molecule-Based Therapeutic Approaches for Targeting Trinucleotide Repeat Disorders, Molecular Neurobiology, https://doi. org/10.1007/s12035-019-01724-4.

[2] David R. FitzPatrick\&R. Frank Kooy et al..(2014)FRA2A Is a CGG Repeat Expansion Associated with Silencing of AFF3, PLOS Genetics ,|Volume 10 | Issue 4 | e1004242.

[3] David R. FitzPatrick\&R. Frank Kooyet al., (2014).A CGG-Repeat Expansion Mutation in ZNF713 Causes FRA7A: Association with Autistic Spectrum Disorder in Two Families, Human Mutation, DOI: 10.1002/hum u.22683.

[4] Shoji Tsuji et al (2019), Noncoding CGG repeat expansions in neuronal intranuclear inclusion disease, oculopharyngodistal myopa thy and an overlapping disease, Naturegenetics, https://doi.org/10.1038/s41588-019-0458-z.

[5] C.M. Rodriguez \& P.K. Todd., (2019) New pathologic mechanisms in nucleotide repeat expansion disorders, Neurobiology of Disease 130, 104515.

[6] Martin JP, Bell J., (1943) A pedigree of mental defect showing sex linkage. J Neurol Psychiatry 6(3-4):154-157.

[7] Lubs HA., (1969) A marker X chromosome. Am J Hum Genet 21(3):231-244. 
[8] Lozano R, AzarangA, Wilaisakditipakorn T, Hagerman RJ., (2016) Fragile X syndrome: a review of clinical management. Intractable Rare Dis Res 5(3):145-157. https://doi.org/10. 5582/irdr.2016.

[9] Ciaccio C, Fontana L, Milani D, Tabano S ,Miozzo M, Esposito S., (2017) Fragile X syndrome: a review of clinical and molecular diagnoses. Ital J Pediatr 43:39. https://doi.org/ 10.1186/s13052- 017-0355-y

[10] Fernandez-Carvajal I, Walichiewicz P, Xiaosen X, Pan R, Hagerman PJ, TassoneF .,(2009) Screening for expanded alleles of the FMR1 gene in blood spots from newborn males in a Spanish population. J Mol Diagn 11(4):324-32 9. https://doi.org/10.2353/jmoldx.2009.080173

[11] Hagerman RJ, LeeheyM, HeinrichsW, Tassone F, WilsonR, Hills J, Grigsby J, Gage B et al .,2001) Intention tremor, parkinsonism, and generalized brain atrophy in male carriers of fragile X. Neurology 57(1):127-130

[12] Tassone F, Hagerman RJ, Taylor AK, Gane LW, Godfrey TE, Hagerman PJ .,(2000) Elevated levels of FMR1 mRNA in carrier males: a new mechanism of involvement in the fragile-X syndrome. Am J Hum Genet 66(1):615. https://doi.org/10.1086/302720.

[13] Tassone F, Hagerman RJ, Garcia-Arocena D, Khandjian EW, Greco CM, Hagerman PJ .,(2004) Intranuclear inclusions in neural cells with premutation alleles in fragile $\mathrm{X}$ associated tremor/ataxia syndrome. J Med Gene t 41(4):e43

[14] Brussino A, Gellera C, Saluto A, Mariotti C, Arduino C, Castellotti B, Camerlingo M, de Angelis V et al .,(2005) FMR1 gene premutation is a frequent genetic cause of lateonset sporadic cerebellar ataxia. Neurology 64 (1): 145-147. https://doi.org/10.1212/01wnl.00 $00148723.34893 \mathrm{f}$

[15] Van Esch H, Dom R, Bex D, Salden I, Caeckebeke J, Wibail A, Borghgraef M, Legius $\mathrm{E}$ et al ., (2005) Screening for FMR-1 premutations in 122 older Flemish males presenting with ataxia. Eur $\mathrm{J}$ Hum Genet 13(1):121-123. https://doi.org/10.1038/sj.ejhg. 5201312

[16] Dombrowski C, Levesque S, Morel ML, Rouillard P, Morgan K, Rousseau F ., (2002) Premutation and intermediate-size FMR1 alleles in 10572 males from the general population: Loss of an AGG interruption is a late event in the generation of fragile $X$ syndrome alleles. Hum Mol Genet 11(4):371378.

[17] Rousseau F, Rouillard P, Morel ML, Khandjian EW, Morgan K.,(1995) Prevalence of carriers of premutation-size alleles of the FMRI gene- and implications for the population genetics of the fragile $\mathrm{X}$ syndrome. Am J Hum Genet 57(5):1006-1018.

[18] Jacquemont S, Hagerman RJ, Leehey MA, Hall DA, Levine RA, Brunberg JA, Zhang L, Jardini $\mathrm{T}$ et al .,(2004) Penetrance of the fragile Xassociated tremor/ataxia syndrome in a premutation carrier population.Jama291(4):460 469. https://doi.org/10.1001/jama.291.4. 460

[19] Coffey SM, Cook K, Tartaglia N, Tassone F, Nguyen DV, Pan R, Bronsky HE, Yuhas J et al .,2008) Expanded clinical phenotype of women with the FMR1 premutation. Am J Med Genet A 146a(8): 1009-1016. https://doi.org/1 0.1002/ajmg.a.32060.

[20] Jacquemont S, Hagerman RJ, Leehey M, Grigsby J, Zhang L, Brunberg JA, Greco C, Des Portes V et al., (2003) Fragile Xpremu tation tremor/ataxia syndrome: molecular, clinical, and neuroimaging correlates. A $\mathrm{m} \mathrm{J}$ Hum Genet 72(4):869-878.https:/doi.o $\mathrm{rg} / 10.1086 / 374321$

[21] Hunsaker, M. R. et al.,(2011) Widespread noncentral nervous system organ pathology in fragile $\mathrm{X}$ premutation carriers with fragile $\mathrm{X}$ associated tremor/ataxia syndrome and CGG knock-in mice. Acta Neuropathol.122, 467479 .

[22] Bahlo, M. et al.,(2018) Recent advances in the detection of repeat expansions with short-read next-generation sequencing. F1000Res. 7, 736 .

[23] Kalantaridou SN, Naka KK, Papanikolaou E, Kazakos N, Kravariti M, Calis KA, Paraskevaidis EA, Sideris DA et al., (2004) Impaired endothelial function in young women with premature ovarian failure: normalization with hormone therapy. J Clin Endocrinol Metab 89(8):3907-3913. https://doi.org/10.1210/jc.20 04-0015

[24] Gallagher JC., (2007) Effect of early menopause on bone mineral density and fractures. Menopause (New York, NY) 14 (3 Pt 2):567-571. https://doi.org/10.1097/gme.0b0 $13 \mathrm{e} 31804 \mathrm{c} 793 \mathrm{~d}$

[25] Atsma F, Bartelink ML, Grobbee DE, van der Schouw YT., (2006) Postmenopausal status and early menopause as independent risk factors for cardiovascular disease: a meta-analysis. Menopause (New York, NY) 13(2):265-279. https://doi.org/10.1097/01.gme.

[26] van der Stege JG, Groen H, van Zadelhoff SJ, Lambalk CB, Braat DD, van Kasteren YM, van Santbrink EJ, Apperloo MJ et al .,(2008) Decreased androgen concentrations and diminished general and sexual well-being in women with premature ovarian failure. Menopause (New York, NY) 15(1):23-31

[27] Satoyoshi, E. \& Kinoshita, M., (1977) Oculop ha ryngodistal myopathy. Arch. Neurol. 34, 8992. 
[28] Durmus, H. 00et al., (2011) Oculopharyngodistal myopathy is a distinct entity: clinicaland genetic features of 47 patients. Neurology 76, 227-235.

[29] Lindenberg, R., Rubinstein, L. J., Herman, M. M. \& Haydon, G. B. A. (1968) light and electron microscopy study of an unusual widespread nuclear inclusion body disease. A possible residuum of an old herpesvirus infection. Acta Neuropathol. 10, 54-73.

[30] Haltia, M., Somer, H., Palo, J. \& Johnson, W. G. (1984) Neuronal intranuclear inclusion disease in identical twins. Ann. Neurol. 15, 316-321

[31] Sone, J. et al.,(2016) Clinicopathological features of adult-onset neuronal intranuclear inclusion disease. Brain 139, 3170-3186

[32] Takahashi-Fujigasaki, J., Nakano, Y., Uchino, A. \& Murayama., (2016) S. Adult-onset neuronal intranuclear hyaline inclusion disease is not rare in older adults. Geriatr. Gerontol. Int. $16,51-56$.

[33] Kimber, T. E. et al.,(1998) Familial neuronal intranuclear inclusion disease with ubiquitin positive inclusions. J. Neurol. Sci. 160, 33-40.

[34] Sone,J. etal.(2005)Neuronal intranuclear hyaline inclusion disease showing motorsensory and au tonomic neuropathy. Neurology 65, 1538-1543.

[35] Yamaguchi, N. et al. (2018) ,An autopsy case of familial neuronal intranuclear inclusion disease with dementia and neuropathy. Intern. Med. 57, 3459-3462.

[36] Sone, J. et al. (2014) Neuronal intranuclear inclusion disease cases with leukoencephalopat hy diagnosed via skin biopsy. J. Neurol. Neurosurg.Psychiatry 85, 354-356.

[37] Sone, J. et al. (2011) Skin biopsy is useful for the antemortem diagnosis of neuronal intranuclear inclusion disease. Neurology 76, 1372-1376.

[38] Nakano, Y. et al.(2017) PML nuclear bodies are altered in adult-onset neuronal intranuclear hyaline inclusion disease. J. Neuropathol. Exp. Neurol. 76, 585-594.

[39] Takumida, H. et al.(2017) Case of a 78-yearold woman with a neuronal intranuclear inclusion disease. Geriatr. Gerontol. Int. 17, 2623-2625.

[40] Doi, K. et al. (2014) Rapid detection of expanded short tandem repeats in personal genomics using hybrid sequencing. Bioinformatics 30, 815-822.

[41] Fiddes, I. T. et al. (2018) Human-specific NOTCH2NL genes affect Notch signaling and cortical neurogenesis. Cell 173, 1356-1369.

[42] Zhao, J. et al. (2015) Clinical and muscle imaging findings in 14 mainland Chinese patients with oculopharyngodistal myopathy. PLoS ONE 10, e0128629.

[43] Uyama, E., Uchino, M., Chateau, D. \& Tomé, F. M.(1998) Autosomal recessive oculopharyngodi stal myopathy in light of distal myopathy with rimmed vacuoles and oculopharyngeal muscular dystrophy. Neuromuscul. Disord. 8, 119-125.

[44] Satoyoshi, E. (1990)Distal myopathy. Tohoku J. Exp. Med. 161, 1-19.

[45] Jing Huang, Wenxiang Zhang, Yingchun Liu, Ying Liu, Jing Wang \& HongJiang (2019) Association between the FMR1 CGG repeat lengths and the severity of idiopathicprimary ovarian insufficiency:ameta analysis, Artificial Cells, Nanomedicine, and Biotechnology,47:1, 3116-3122, DOI:10.1080/21691401.2019.1645 153. Ma et al. (2019) Composition of the Intranuclear Inclusions of Fragile X-associated Tremor/Ataxia Syndrome Acta Neuropathologi ca Communications, 7:143

[46] Alexander E Linsalata et al (2019), DDX3X and specific initiation factors modulate FMR1 repeat-associated non-AUG-initiated translation, EMBO reports 20: e47498 |,DOI 10.15252/em br.201847498

[47] Ma et al.(2019), The prevalence of CGG repeat expansion mutation in FMR1 gene in the northern Chinese women of reproductive age BMC Medical Genetics 20:81 https://doi.or g/10.1186/s12881-019-0805-z.

[48] Hoem G, Bowitz Larsen K, Øvervatn A, Brech A, LamarkT,Sjøttem E and Johansen T (2019) TheFMRpoly Glycine Protein Mediates Aggre gate Formation and Toxicity Independent of the CGG mRNA Hairpin in a Cellular Model for FXTAS.Front. Genet.10:249.doi:10.3389/fgen e.2019.00249.

[49] Mariel Ormazábala, Andrea Solaria, Lic. Lucía Espechea ,Téc. Tania Castroa, y Lic. Noemí Buzzalinoa,(2019)Fragilidad del X y otrasenti dadesasociadas al gen FMR1: estudio de $28 \mathrm{fa}$ miliasafectadasArch Argent Pediatr ;117(3):e 25 7-e262 / e257.

[50] Wise, T. L. (2016). Changes in insulin-like growth factor signaling alter phenotypes in Fragile X Mice. Genes, Brain and Behavior, 16(2), 241-249. doi:10.1111/gbb.12340.

[51] Farzin, F., Perry, H., Hessl, D., Loesch, D., Cohen, J., Bcacalman, S. Hagerman, R. (2006). Autism Spectrum Disorders and Attention-Def icit/Hyperactivity Disorder in Boys with the Fra gile X Premutation. Journal of Developmental \& Behavioral Pediatrics, 27 (Supplement2), S137-S144.doi:10.1097/00004703-20060400 2-00012.

[52] Zhang, H., Liu, X., Zhang, C., Mundo, E., Macc iardi, F., Grayson, D. R.,Holden, J. J. A. (2002). Reelin gene alleles and susceptibility to autism spectrum disorders. Molecular Psychiat 
ry, 7(9), 1012-1017. doi:10.1038/sj.mp.40011 24.

[53] Franke, P., Maier, W., Hautzinger, M., Weiffe nbach, O., Gänsicke, M., Iwers, B. Froster, U. (1996). Fragile-X carrier females: Evide nce for a distinct psychopathological phenotype? Ame rican Journal of Medical Genetics, 64(2), 334339. doi:10.1002/(sici)1096-8628(19960809)6 $4: 2<334$.

Citation: Dr Rajib Dutta, Swatilekha Roy Sarkar. Non coding CGG repeat expansion diseases: An update. ARC Journal of Neuroscience. 2019; 4(1):15-21. doi: dx.doi.org/10.20431/2456-057X 0401002.

Copyright: (C) 2019 Authors. This is an open-access article distributed under the terms of the Creative Commons Attribution License, which permits unrestricted use, distribution, and reproduction in any medium, provided the original author and source are credited. 